\title{
A REVISION OF THE GENUS ZILORA
}

\author{
By EDITH W. MaNK \\ Lawrence, Mass.
}

The genus Zilora belongs among those Melandryidæ which are characterized by (1) a thorax narrower at the base than the base of the elytra, (2) depressions at the base of the thorax, (3) an abdomen where the first two segments are decidedly longer than the last three.

As represented in the United States, the genus includes beetles with the head short, the antennæ slender, the last segment of the maxillary palpi securiform, at least the posterior part of the lateral edge of the thorax sharp, parallel sided elytra. On the under side, the episternal sutures are present, the anterior coxal cavities have a lateral fissure, the trochantin is visible, the middle coxæ are separated by the mesosternum. The pubescence, except in Zilora nuda where all types of erect pubescence are wanting, consists of two kinds. The general pubescence is suberect and plentiful but there are also fine erect hairs in rows, only seen when the specimen is viewed in profile. The erect hairs either form complete rows or are confined to the rear half of the elytra.

Of the American Ziloras previously described, the type of Zilora hispida Lec. has been examined. The type of Zilora nuda Prov. is known to me personally only from description, but specimens of $n u d a$ in my possession have been compared for me by Mr. N. M. Comeau with the type which is in the Museum at Quebec and they were found to be identical with the type. A specimen labeled as the type of Zilora canadensis Hausen is in the Winn collection which is now in the collection at McGill University. Through the kind offices of Mr. G. Chagnon, it has been possible to examine this specimen. The specimen bearing the type label was found to be a Scotochroa and not a Zilora. It seems probable that the type is lost for this beetle does not have the securiform terminal segment of the palpi, nor the erect hairs mentioned by Hausen himself as present in Zilora, nor is the punctuation 
of the head and thorax more dense and fine than on the wing covers as he describes it. Moreover, his specimen as he says "seems to be a male, the penis is protruded and bilobed at the extremity." The specimen at McGill is a female.

From the table given below, Zilora canadensis Hausen has, therefore, been omitted.

Thanks are due to Mr. Ralph Hopping who placed at my disposal his Ziloras, including long series of Zilora nuda Prov. and the new western species, Zilora occidentalis; to Mr. P. J. Darlington Jr. of the Museum of Comparative Zoology at Harvard University for access to all the Ziloras in that collection; and to Mr. H. C. Fall for the use of all his material in this genus and for his unfailing advice in the revision of this genus. The types of Zilora alabamensis and occidentalis are in Mr. Fall's collection.

\section{TAble of American Species of Zilora}

A. Erect pubescence, smooth area margining the eye posteriorly, lateral edge of abdominal segments margined the entire length of the body, male with denser patch of pubescence on the inferior edge of middle and hind femora.

B. Hind angle of thorax very nearly rectangular, color fuscocastaneous, species of Eastern North America.

C. Surface of scutellum rough but without well defined round punctures, hind angles of thorax slightly reflexed, narrower compared with length than in $Z$. hispida Lec. The type is from Saraland, Alabama. alabamensis n. sp.

CC. Surface of scutellum showing definite punctures, not rough, hind angles of thorax not reflexed, posterior angles of scutellum, also, not reflexed, body slightly wider compared with the length than in $Z$. alabamensis. The type is from N. H. hispida Lec.

BB. Hind angle of the thorax perceptibly obtuse, color darker than in the above species, from Western coast of North America. The type is from Kern Co., Cal. occidentalis $\mathrm{n}$. $\mathrm{sp}$.

AA. No erect pubescence, no smooth area margining the eye posteriorly, lateral edge of abdominal segments not margined beyond the anterior part of the second segment, area at middle of thorax quite smooth with only a few punctures, terminal segment of maxillary palpi not as large as in the other species of Zilora, male without denser patch of pubescence on the inferior edge of middle and hind femora. The type is from Cape Rouge, Quebec.

nuda Prov.

Zilora alabamensis $n$. sp.

More slender than hispida. Punctures on head coarser 
and deeper than in hispida. Eyes bulging, with smooth rim posterior to the eye. Forehead above front flattened.

Thorax finely margined at base; sides sharp clear to front edge although anterior quarter of margin is much less distinct; posterior angles of thorax very nearly rectangular, slightly reflexed. Thorax coarsely punctured, sometimes with cross ridges between punctures over middle part of thorax; two basal impressions not as deep as in hispida. Elytra and thorax with erect and suberect pubescence. Erect pubescence in complete rows. Sides of elytra fairly parallel, rows of punctures poorly defined. Scutellum broad with posterior angles slightly reflexed; punctures on the scutellum not well defined, surface rough, however. On under surface large fissure on the anterior coxal cavity with trochantin plainly visible. Abdomen margined laterally clear to the tip.

Length 6-7 mm.; width 2-2.5 mm.

The type and two other specimens examined were from Saraland, Ala. and were collected by Mr. H. P. Loding of Mobile.

\section{Zilora hispida Lec.}

Head short from antennæ down; membranous piece joining labrum to front; head fairly hairy; punctuation close on front, less so posteriorly; eyes bulging with smooth rim bordering them on the posterior edge. Thorax finely margined at base and laterally more than half way to anterior edge; depressions on basal part of thorax deep and sharply defined; posterior angles of thorax very nearly rectangular, not reflexed; punctuation of thorax fairly close; at base decidedly narrower than the width of the elytra.

On under surface, suture between prosternum and episternum present but flat; lateral fissure present on anterior coxal cavity; trochantin visible. Middle coxae separated by process of the mesosternum. Rows of erect hairs running the length of the elytra. The pubescence both erect and suberect. The pubescence is longer than in the other species, making the specimens look more hairy.

Abdomen margined laterally to the tip.

Length 5-5.1 mm.; width 1.5-2 mm.

The type is marked N. H. Other specimens have been examined marked Mt. Washington. 


\section{Zilora occidentalis $\mathrm{n}$. sp.}

Punctuation, in general, more sparse than in the eastern forms. Front of head above eyes not as bulging as in hispida. Smooth area present posterior to eye. Lateral margin of thorax sharp at least $3 / 4$, of distance to anterior margin. Hind margin of thorax perceptibly obtuse. Scutellum very finely and profusely punctured. The rows of erect hairs on the elytra confined to apical half. Color darker than in the preceding species. Abdomen margined laterally to the tip.

Length $7.1 \mathrm{~mm}$.; width $2-2.5 \mathrm{~mm}$.

The type is from Kern Co., Cal. Other specimens were examined from Fresno Co., Cal., Seattle, Wash., Trinity Valley, B.C., Merritt, B.C., Pender Harbor, B.C., and Aspen Grove, B.C.

\section{Zilora nuda Prov.}

No erect pubescence. No traces of punctures on the elytra. Depression at middle of thorax at base quite smooth with only a few punctures. Terminal segment of maxillary palpi not as large as in other species of the genus. Slightly hairy front but pubescence not erect. No smooth rim bordering the eye posteriorly. Much coarser punctures on scutellum than in Zilora occidentalis.

Lateral edge of the abdominal segments not margined beyond the beginning of the second segment, while in the other Ziloras the abdominal margin is continuous to the tip of the abdomen.

Length $7 \mathrm{~mm}$.; width $2 \mathrm{~mm}$.

The type is from Cape Rouge, Quebec. Specimens have been examined from Duparquet, Quebec, Can. 

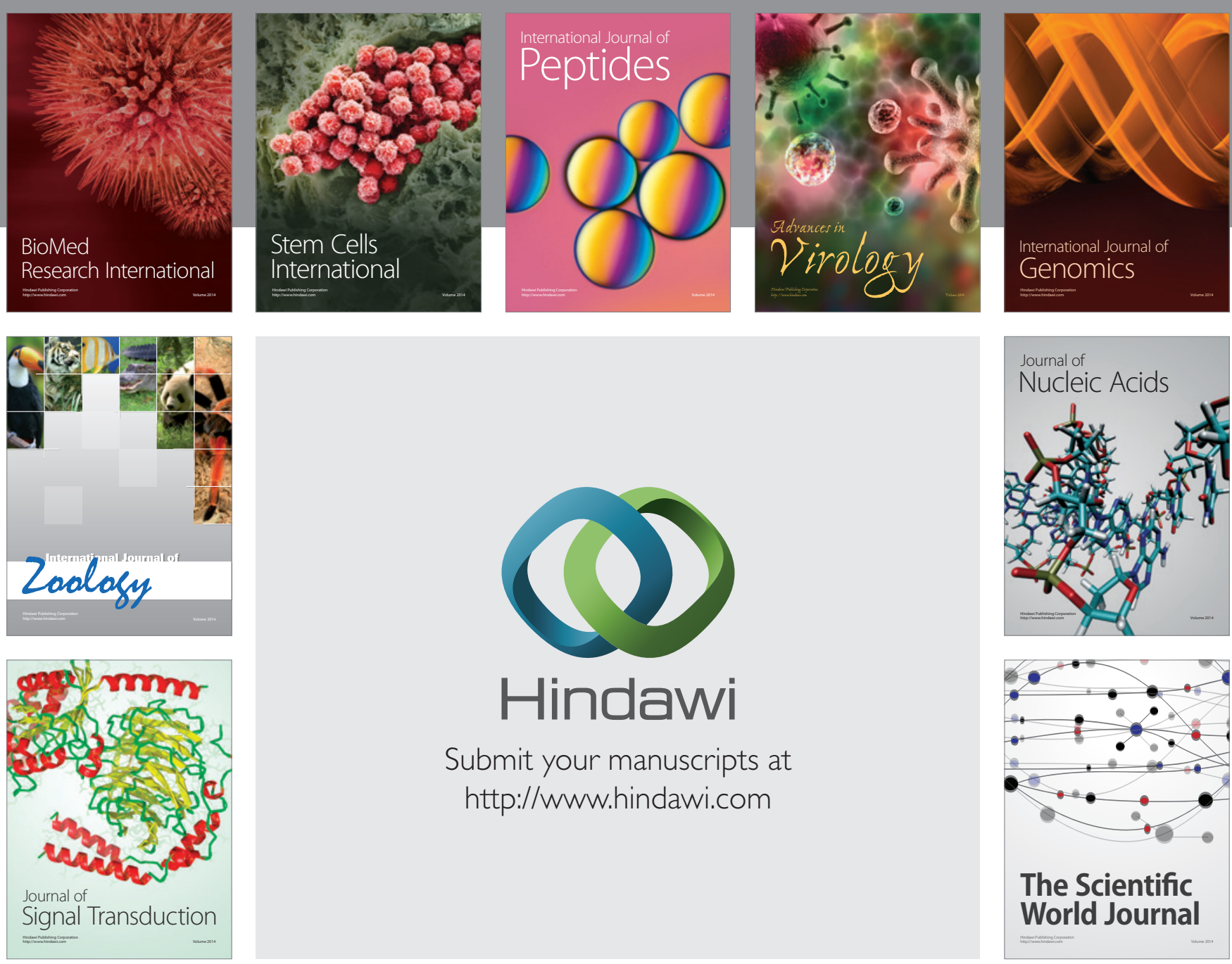

Submit your manuscripts at

http://www.hindawi.com
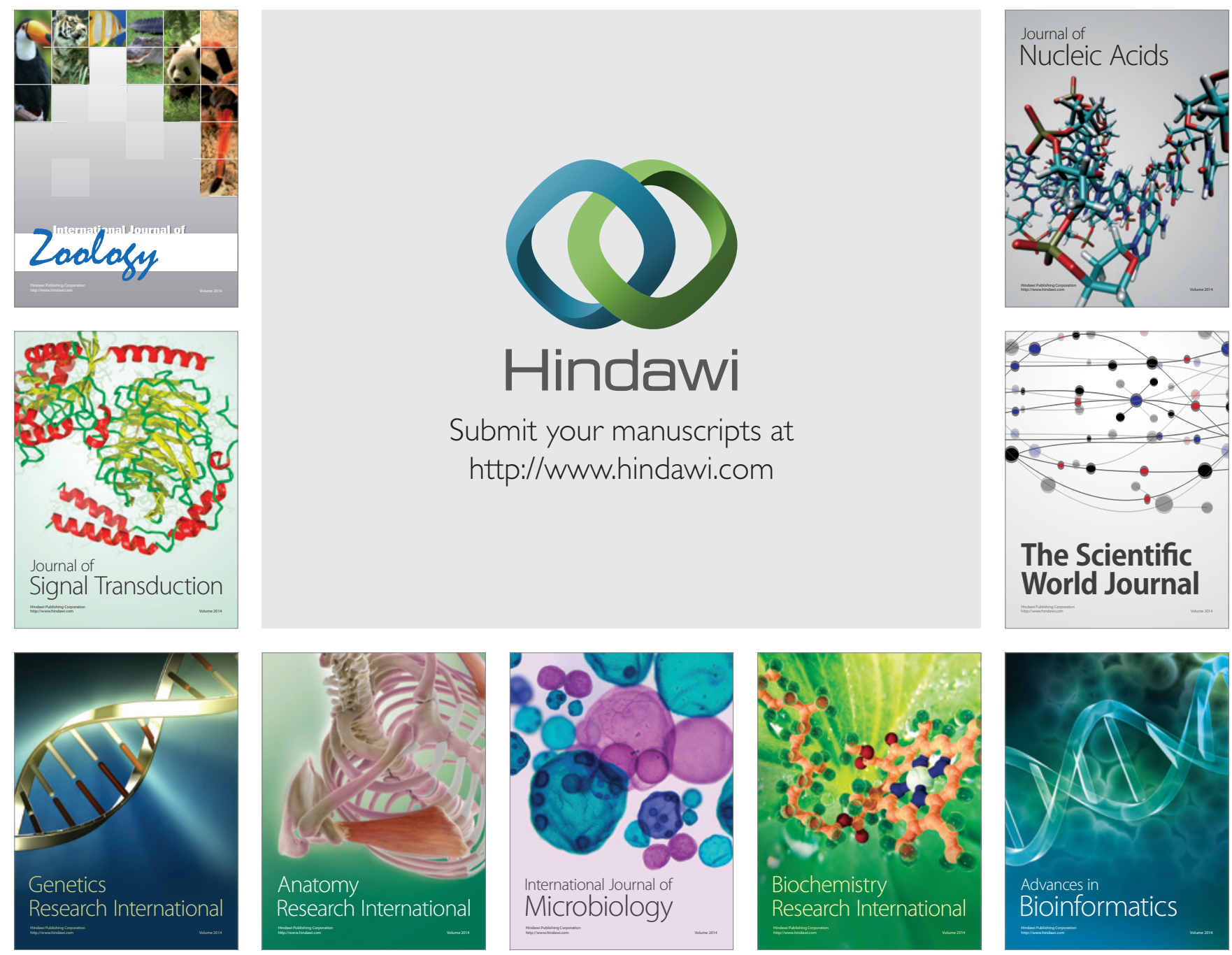

The Scientific World Journal
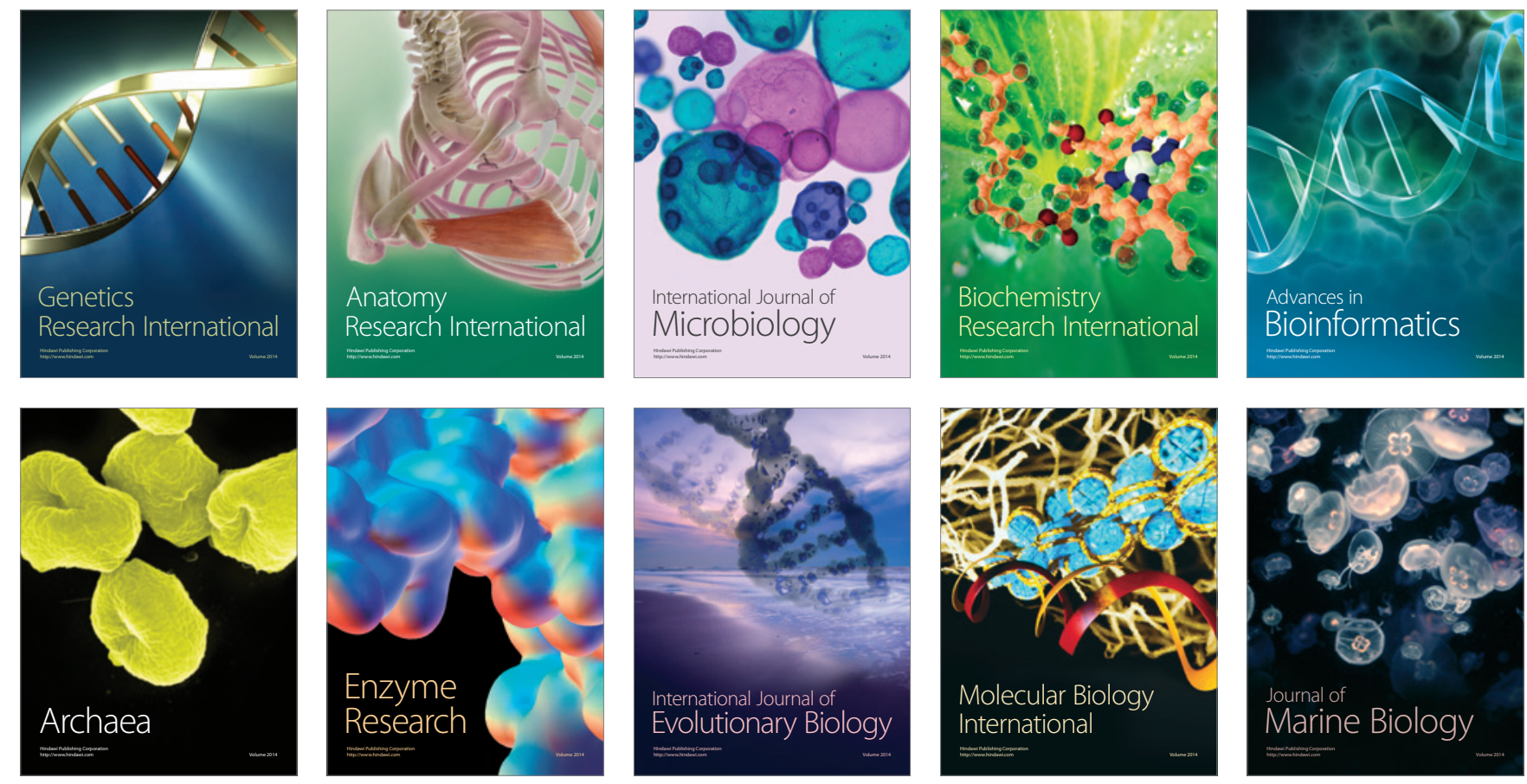